\title{
Mais pluralismo: considerações sobre a relevância do Movimento Por uma Economia Pós-Autista
}

More Pluralism: considerations about the Post-Autistic Economics Movement relevance

\begin{abstract}
The purpose of this paper is to analyze the proposal of the Post-Autistic Economics Movement (PAE), since its origins until our days, in the context of the current debate about the need of pluralism as a desirable standard for the evolution of economics, especially for the teaching of the discipline. The paper discusses the scientific character of economics, taking into account PAE's criticism, looking at this movement's history and recent developments, in the light of the criticism on economic thought raised after the effects of 2008 Financial Crisis. In particular, the paper focuses on the possible impacts of movements like this in the teaching of economics on this post-crisis environment, which demands greater pluralism and methodological freedom in economic thought and methodology.
\end{abstract}

\section{Keywords}

applied social sciences; methodology of Economics; pae movement.

JEL Codes B41, B50, A22.

\author{
Daniel de Santana Vasconcelos (1) \\ Maísa Goulart S. Ribeiro (2) \\ Ramon Garcia Fernandez ${ }^{(3)}$ \\ (1) Universidade Federal de Santa Catarina \\ (2) Universidade Federal do $\mathrm{ABC}$ \\ (3) Universidade Federal do $\mathrm{ABC}$
}

\section{Resumo}

O objetivo deste trabalho é analisar a proposta do Movimento Por uma Economia Pós-Autista (MPEPA), a partir da situação atual na evolução do pensamento econômico e do debate que tem surgido sobre pluralismo como princípio desejável para a ciência econômica, especialmente no seu ensino. O trabalho discute o caráter científico da economia a partir de questionamentos levantados pelo MPEPA, bem como situa a história do movimento e seus recentes desenvolvimentos, no contexto das diversas críticas enfrentadas pela ciência econômica no periodo posterior à crise financeira iniciada em 2008. Avaliam-se os possiveis impactos de movimentos como o MPEPA para o ensino de economia, num ambiente que demanda maior pluralismo e liberdade metodológica nas abordagens dessa ciência.

\section{Palavras-chave}

ciências sociais aplicadas; metodologia da ciência econômica; movimento por uma economia pós-autista.

Códigos JEL B41, B50, A22. 


\section{Introdução}

"And the role of economists in all of this? (...). It is their job to chart the course of economic activity and to explain how the economy works; naturally, then, we look to them to help us make sense of what, on the face of it, is a senseless state of affairs. And yet they are the first ones to demonstrate that they understand nothing. This has not prevented them, however, from showing still greater arrogance (...) - whereas it is their own blindness to social reality that is responsible for a large share of the world's troubles."

(Jean-Pierre Dupuy, 2014, p. xi)

Encontramos em todo o mundo uma onda crítica com relação ao estado da ciência econômica e ao seu ensino, particularmente após a crise financeira de 2008; essa reação questiona muitos dos pressupostos sobre os quais foi construído um mainstream econômico com a pretensão de ser semelhante a uma hard science formal. A discussão, no entanto, não é tão nova quanto parece à primeira vista. Desde muito tempo atrás registra-se uma insatisfação com a homogeneização da forma de fazer e ensinar economia dentro de padrões atuais, ou seja, adotando o mainstream econômico de forma acrítica. A crise financeira de 2008 deu novo fôlego a esses movimentos questionadores.

Nesse contexto, o chamado "Manifesto por uma Economia Pós-Autista" (MPEPA, doravante), lançado em 2000 por estudantes franceses e que já tinha gerado um impacto importante já antes da crise, delineou os contornos de um movimento amplo de contestação do domínio do mainstream na economia. Esse movimento soma-se a posturas críticas defendidas por autores como Fullbrook (2003), Lawson (2003) e McCloskey (2001), que advogavam, desde antes de 2008, a necessidade de reformular os currículos dos cursos de economia, em busca de uma maior aderência à realidade dos tratamentos dados pela ciência ao estudar os problemas econômicos.

A primeira reação ao deparar-se com o termo "Economia Pós-Autista" é o estranhamento, dada a falta de relação óbvia entre autismo e economia. Todavia, não resulta difícil entender qual era a crítica que tinham em mente os autores do manifesto. Um trecho da carta que impulsionou esse movimento no início de 2000 dizia: "We no longer want to have this autistic science imposed on us!"1 Neste sentido, com base no histórico do site oficial 1 Encontrado em <http://www.paecon.net/PAEReview/wholeissues/issue2.htm>. Acesso: 10 ago. 2015. 
do movimento, PAECON" , a mesma petição explicitava "a real schizophrenia created by making modelling 'an end in itself' and thereby cutting economics off from reality and forcing it into a state of 'autism'." ${ }^{\prime \prime}$. A explicação dos estudantes envolvidos no manifesto resume o sentimento daquele momento, denunciando que os praticantes do mainstream econômico, e particularmente aqueles que o ensinam nos cursos de graduação e pós-graduação em economia, fechavam-se num mundo de abstrações teóricas irrealistas, autorreferenciado e pouco aberto a críticas. É nesse sentido no qual se afirmava que o comportamento mainstream seria autista.

Vale mencionar que o nome oficial do movimento originalmente foi "Movimento Estudantil para a Reforma do Ensino de Economia". O nome posteriormente utilizado passou a ser, porém, "Movimento por uma Economia Pós-Autista", que é o que usaremos neste artigo. Inclusive, a principal publicação do movimento nessa fase inicial ganhou o nome de Post-Autistic Economic Review. Todavia, como aponta Klaus Mohn (2010), usar um diagnóstico psiquiátrico como argumento retórico para criticar adversários apresenta problemas éticos em relação às pessoas que sofrem com a doença, e ao mesmo tempo, certamente constitui uma barreira a qualquer diálogo construtivo com pessoas que defendem a visão criticada. Nesse sentido, o nome da revista mudou para o de Real World Economics Review a partir do $\mathrm{n}^{\circ} 45$, publicado de 2008. Posteriormente, com o próprio crescimento do movimento, foi criada a partir deste mesmo impulso a World Economics Association, em maio de 2011.4 A partir dessa data, outras iniciativas foram criadas, destacando-se a International Student Initiative for Pluralism in Economics (ISIPE), criada em 2014 e que no início de 2017 agregava 82 associações estudantis de 31 países. ${ }^{5}$

Obviamente, essas críticas não são novas; a economia ortodoxa sempre foi criticada pelas correntes heterodoxas. O que queremos destacar aqui é que a forma específica que o mainstream assumiu a partir do final dos anos 1980 (caracterizada pelo novo consenso macroeconômico, o equilíbrio geral a la Arrow-Debreu e os modelos de crescimento endógeno, somado

2 PAECON é a sigla em inglês do movimento: Post Autistic Economics Movement, cujo site é http://www.paecon.net/.

3 Encontrado em<http://www.paecon.net/PAEReview/wholeissues/issue1.htm>. Acesso: 10 ago. 2015.

4 Veja-se https://www.worldeconomicsassociation.org/. A associação hoje publica três periódicos e uma série de livros, além de promover outras atividades.

5 Maiores informações sobre a associação disponíveis em http://www.isipe.net/. 
à explosão do uso de técnicas econométricas), bem como o modelo de treinamento de economistas dentro dessa perspectiva, provocaram questionamentos mesmo entre as principais cabeças da corrente dominante. Inclusive, esses questionamentos tinham levado, em 1988, à criação de uma Comissão sobre os Estudos de Pós-Graduação em Economia, presidida pela professora Anne Krueger, economista reconhecidamente ortodoxa. Essa comissão elaborou um relatório com fortes críticas ao ensino de economia e à geração que estava sendo assim formada, que poderia estar composta por "idiots savants" (Comission on Gradute Education in Economics, 1991, p.1035). ${ }^{6}$ Pouco depois apareceu, como anúncio na American Economic Review de maio de 1992, uma petição organizada por Geoffrey Hodgson, Uskali Mäki e Deirdre McCloskey, assinada por 44 economistas importantes (quatro deles ganhadores do Memorial Nobel) defendendo maior pluralismo no treinamento e contratação de economistas. ${ }^{7}$ Todavia, apesar do peso dos nomes que integraram essas iniciativas, seus resultados podem ser considerados pífios. Na virada do milênio nada havia mudado nesse sentido.

Este processo marcou, porém, uma mudança de atitude em parte da comunidade dos economistas. As críticas tradicionais à ortodoxia, e as próprias defesas ortodoxas, tipicamente assumiam que havia uma visão correta na economia (identificada com o mainstream), ao passo que as demais estariam erradas ou seriam talvez irrelevantes. A ideia normativa da defesa do pluralismo, ou seja, a de que era bom para a ciência como um todo que uma pluralidade de visões existisse (Mäki, 1997) foi avançando lentamente.

Um marco nessa mudança de espírito certamente foi a defesa do pluralismo proposta por Caldwell (1982). ${ }^{8}$ Um símbolo claro desse ethos diferente surgiu pouco mais de uma década depois. Em 1993 um grupo de indivíduos e de associações, todos eles defensores da heterodoxia, reuniram-se para formar uma associação, a "Internacional Conference of Associations for the Reform of Economics" (ICARE). Pouco depois esses grupos mudaram a orientação da associação, substituindo a defesa da mudança pela da coe-

6 Segundo o relatório, "The Commission was formed in response to what seemed like a growing chorus of complaints about the nature of economic research and training in economics departments at most universities. (...) This view point seemed to be shared by a sufficiently large number of people inside and outside the profession that it merited careful scrutiny" (Comission on Gradute Education in Economics, 1991, p.1035).

7 Ver http://www.feed-charity.org/new-page-3.htm. Acesso: 15 jan. 2017.

8 No Brasil o tratamento pioneiro dessa questão encontra-se em Bianchi (1992). 
xistência e diálogo entre as diferentes escolas, apesar de continuarem sendo essencialmente associações heterodoxas, de modo que alteraram o nome para ICAPE, com a substituição de "Reform" por "Pluralism".9 Destacamos, finalmente, a publicação da obra "Pluralism in Economics", primeira coletânea discutindo o pluralismo em Economia (Salanti e Screpanti, 1997). Esta coletânea, incluindo artigos de muitos dos principais especialistas em metodologia econômica, mostra por um lado que, mesmo com divergências quanto ao escopo do pluralismo ${ }^{10}$, o termo tinha encontrado um lugar central nas discussões, sinalizando um novo espírito dos tempos na ciência econômica.

\section{Manifesto por uma Economia Pós-Autista}

Os pontos elencados pelos estudantes de economia franceses como necessários para que fosse possível livrar-se do caráter "autista" que rondava, segundo eles, a ciência econômica, estavam centrados, na primeira versão do manifesto (junho de 2000) em quatro pilares:

i) desejo de escapar dos mundos imaginários;

ii) reflexão sobre o uso descontrolado da matemática;

iii) defesa do pluralismo das abordagens em economia;

iv) chamada ao corpo docente para atentar a esses fatos. ${ }^{11}$

Em um momento posterior, também alguns professores expressaram seu descontentamento com o que acontecia no ensino e pesquisa de economia naquele mesmo contexto, criticando a expansão do mainstream econômico, baseado no modelo de equilíbrio geral, na hipótese de expectativas racionais, nos mercados eficiente, e na marginalização de todos os programas de pesquisa não alinhados a esse núcleo. Esses professores de universidades francesas, então, redigiram um manifesto de apoio aos estudantes, que abordou cinco críticas dirigidas:

i) À exclusão de teorias que não sejam de recorte neoclássico ${ }^{12}$;

9 Há muitas associações de economistas heterodoxos em diversos países do mundo. Para um mapeamento abrangente dos movimentos heterodoxos em diversos países (com ênfase para os grupos anglo-americanos), ver Lee (2009).

10 Um dos organizadores da coletânea sugeriu que apesar da atitude geralmente favorável ao pluralismo entre os metodólogos, "... as soon as we ask them to specify what they mean by this term, we discover a puzzling array of quite diferente answers" (Salanti, 1997, p.7).

11 A carta original está disponível em <http://www.paecon.net/PAEtexts/a-e-petition.htm>. 12 A petição original usa o termo neoclássico; observamos que os termos mainstream, or- 
ii) Ao ensino atual de economia, pelo descompasso existente entre a teoria e os fatos, apontando para a baixa aderência das teorias aos dados da realidade econômica;

iii) Ao uso de matemática como um fim de si mesma, e não como uma ferramenta para a pesquisa teórica;

iv) Aos métodos de ensino que excluem ou proíbem o pensamento crítico;

v) À falta de pluralidade de abordagens, necessária pela complexidade dos objetos analisados. ${ }^{13}$

Percebe-se que ambos os movimentos tinham um foco comum, com as solicitações dos professores se aproximando da insatisfação colocada pelos estudantes franceses. Há, claramente, similaridades na visão acerca da problemática central, propostas de formas diferentes. Visando explorar a aproximação entre as colocações de discentes e docentes, as próximas subseções têm como objetivo central identificar o caráter metodológico que envolve cada uma das críticas acima, relacionando-as entre si e com a literatura.

\subsection{Mundos imaginários, ergodicidade e autismo em economia}

O desejo de escapar dos chamados "mundos imaginários", primeiro ponto abordado pelos estudantes, está relacionado ao segundo tópico dos professores: o descompasso entre o ensino de economia e a realidade econômica. A metodologia dominante no mainstream revela uma grande distância entre os modelos analíticos abstratos e a aderência dos mesmos à realidade. O núcleo principal do mainstream é formado por um conjunto de modelos de uma economia construída a partir de hipóteses muito rígidas, escolhidas por suas propriedades matemáticas específicas, desejáveis para sua demonstração. ${ }^{14}$ Há um descompasso entre a elegância dos modelos teóricos

todoxo e neoclássico são usados no presente trabalho em forma intercambiável, para nos referirmos à posição teórica dominante em economia. Não obstante, mainstream será nossa primeira opção. Estamos cientes de que esses termos podem ter escopos diferentes (Colander, 2000; Dequech, 2007). Para os objetivos deste trabalho, todavia, a sinonímia é aceitável, especialmente porque a crítica do MPEPA se dirige ao conjunto de perspectivas denominadas por esses três termos.

13 Este documento pode ser acessado em: <http://www.paecon.net/PAEtexts/Fr-t-petition. htm>.

14 Essas propriedades devem ser compatíveis com as condições de contorno necessárias para, por exemplo, demonstrar a existência e unicidade das situações de equilíbrio. 
e sua baixa aderência empírica, e um comportamento acrítico quanto às hipóteses e/ou base axiomática que fundamentam tais modelos. Teóricos mainstream, no entanto, consideram aceitáveis modelos que se justificam com base na proposição do "as if" metodológico, postulado por Friedman (1966). Isso provoca críticas, como a da carta do MPEPA: "Furthermore, this gap in the teaching, this disregard for concrete realities, poses an enormous problem for those who would like to render themselves useful to economic and social actors." ${ }^{15}$ Essa crítica à desconexão entre teoria e prática, e entre o mundo abstrato e o mundo real, remonta à crítica ao mainstream realizada pela escola pós-keynesiana tendo como base a questão da ergodicidade (não explicitamente assumido pela ortodoxia) e a crítica do desenvolvimento de modelos abstratos em economia.

Davidson (2012, p. 02) conceitua assim o que ele chama de axioma da ergodicidade: ergodicidadeergodicidadeergodicidade

Ergodic axiom assumes the economic future is already predetermined. The economy is governed by an existing ergodic stochastic process. One merely has to calculate probability distributions regarding future prices and output to draw significant and reliable statistical inferences about the future.

Para essa perspectiva crítica, a hipótese de ergodicidade constituiria a base da matematização do mainstream. Constrói-se assim uma teoria que descreve o mundo como se este pudesse ser compreendido por um processo matemático mensurável e previsível. Para o mainstream, é impossível fazer ciência em economia senão fosse por essa perspectiva de mensurabilidade e completude abstratas.

A utilização do axioma de ergodicidade como fundamento teórico do mainstream fundamenta a tentativa de dar um caráter "verdadeiramente" científico para a economia, como evidenciado por Davidson (2012, p. 04). A ergodicidade permitiria um grau de formalização semelhante ao das denominadas "ciências duras", mas a aplicabilidade deste axioma em economia é questionável, pois ele presume que o futuro da economia seja espelhado exclusivamente na replicabilidade probabilística dos eventos

15 Disponível em: <http://www.paecon.net/PAEtexts/a-e-petition.htm>. Deve-se observar que as deficiências de adequação empírica, bem como o uso de recursos matemáticos ou econométricos de forma ad hoc para demonstrar os resultados previamente desejados dos modelos têm sido objeto de acusação até mesmo por teóricos de dentro ou próximos ao mainstream, como Krugman (2009), Posner (2009:1; 2009:2; 2010), Stiglitz (2014) e Romer (2016). Romer, em particular, lançou uma das mais duras críticas à teoria macroeconômica dos últimos 30 anos, que ele chama "post-real macroeconomics" (Idem, p. 5). 
passados, com incerteza tão somente estocástica, isto é, cuja tendência de longo prazo é nula. ${ }^{16}$ Essa posição leva assim a desconsiderar quaisquer enfoques teóricos que tratem a incerteza como algo fundamental, tal como em Knight (1921) e Keynes (1921). ${ }^{17}$

O axioma da ergodicidade é uma forma de se retirar a incerteza absoluta da teoria econômica. Apesar disso, não é uma exigência para construir uma ciência. Na ciência econômica mainstream, essa incerteza estrutural foi substituída pela incerteza no sentido de Von Neuman-Morgenstern, que é de natureza ergódica, mensurável. Nesse sentido, Davidson (1994, p. 90) evidencia que "Under the ergodic axiom, probability is knowledge, not uncertainty". ${ }^{18}$

Em particular, o instrumental empírico mais característico da economia, a econometria, está fundamentalmente baseado em aproximações ergódicas da realidade, lastreadas em observações passadas de variáveis econômicas. Essas aproximações fazem uso de hipóteses estatísticas em geral muito restritivas que, não raramente, acabam se afastando do mundo real. ${ }^{19}$ Além disso, dentro do mainstream parece ocorrer frequentemente um deliberado desprezo em relação à contra-evidência empírica, isto é, às análises empíricas que apontam para resultados divergentes dos modelos teóricos que costumam ser considerados pelo mainstream como boas aproximações da realidade. ${ }^{20}$

16 A definição matemática de ergodicidade não é trivial. Em termos formais, se a média temporal de um processo estacionário (definido como uma série temporal com covariância

finita e limitada), dado matematicamente por $\bar{y} \equiv(1 / T) \sum_{t=1}^{T} y_{t}^{(1)}$, converge em probabilidade para o valor esperado $E\left(Y_{t}\right)=\int_{-\infty}^{\infty} y_{t} f_{Y_{t}}\left(y_{t}\right) d y_{t}$, tomado de uma amostra de realizações (séries observadas) $\left\{y_{t}^{(1)}, \ldots, y_{t}^{(I)}\right\}$ quando $\mathrm{T} \rightarrow \infty$, esse processo é dito ergódico para a média (Hamilton, 1994, p. 46-7).

17 Knight (1921) explicitamente ressaltou a diferença entre risco (que é probabilisticamente calculável) e incerteza, que não é passível de mensuração. Também Keynes (1921 [2006]) traduziu a noção de incerteza ao descrevê-la de forma direta: "About these matters there is no scientific basis on which to formany calculable probabilty whatever. We simply do not know" (Keynes, 1937, p. 214).

$18 \mathrm{Na}$ mesma linha de raciocínio, Andrade (2011).

19 A crítica de Mandelbrot (1987) é das mais fortes à forma como a econometria trata, por meio de aproximações lineares, problemas complexos e não lineares. Ela faria uso de componentes determinísticos, sujeitos a efeitos de choques aleatórios com propriedades estatísticas muito restritivas nos componentes de erros. Também Mirowski (1986) endossa a crítica. O artigo de Romer (2016) não somente aprofunda esses pontos, mas mostra como resultados diferentes de modelos "consagrados" podem ser obtidos tão somente por mudanças ad hoc nos parâmetros, mesmo que utilizando basicamente as mesmas técnicas e trabalhando sobre os mesmos dados. 20 Um exemplo disso é a forma como foi recebida uma pesquisa empírica de fôlego (Dan- 
Isto reabre a discussão sobre o quanto essa postura empobrece a teoria econômica, comprometendo, também, a relação entre o que é ensinado/ aprendido e o que acontece no mundo real. Mundos não ergódicos, como as sociedades humanas, com toda a sua complexidade histórica e institucional, transformam-se em "anomalias" teóricas quando vistas sob essa perspectiva de perfeita previsibilidade. Em vista disso, o mainstream parece preferir trabalhar exclusivamente com mundos imaginários, como coloca o MPEPA. A crítica a essa forma altamente rígida e abstrata de estudar fenômenos econômicos consiste em reafirmar que o mundo de fato é muito menos previsível do que as teorias mainstream supõem; consequentemente, o passado não é um guia estatístico seguro para o futuro (Davidson, 1994). Autores pós-keynesianos defendem que o axioma da ergodicidade ceda espaço para permitir abordagens que destaquem a postura defensiva dos agentes frente à incerteza absoluta, como em Keynes e Knight: "For Keynes, (...) the belief that inteligent people know that they cannot know the future is an essential element in understanding the operation of our economic world." (Davidson, 2012, p. 5). ${ }^{21}$ Essa postura é mais condizente com a busca de modelos teóricos realistas, atitude defendida pelos proponentes do MPEPA.

Como observação final, ressaltamos que para nós é muito razoável que os economistas se empenhem na construção de uma ciência econômica rigorosa e objetiva, incluindo aí o uso de modelos formais. Apontamos, porém, que estes modelos não deveriam transformar-se num fim em si mesmos. É nesse sentido que consideramos que o axioma da ergodicidade afasta a economia da realidade. Em um mundo ergódico, eventos como grandes crises financeiras estão descartados. Um sistema que tende "naturalmente" ao equilíbrio não pode, em tese, cair vítima de eventos imprevisíveis dessa natureza. Ainda assim, desafiando essa lógica, tais crises ocorrem. ${ }^{22}$

zinger, Van der Haag, Smolensky e Taussig, 1983), lastreada numa amostra de 9.494 famílias, que revelou evidências contrárias à hipótese de consumo do ciclo de vida, de Modigliani. Essa pesquisa, até onde conhecemos, nunca foi refutada por evidências empíricas que sustentassem a hipótese original; não obstante, como em outros casos, o mainstream tem ignorado a evidência contrária.

21 Vale ressaltar que os pós-keynesianos reivindicam fidelidade às proposições de Keynes a respeito de incerteza. Para Keynes, o conceito de incerteza está intimamente relacionado à questão da formação de expectativas, as quais dependem de convenções comportamentais e do estado da confiança com que essas convenções são alcançadas em economias monetárias de produção.

22 Davidson (2012, p. 8) destaca esse ponto: "Theories are not ever conclusively established and can be replaced when events are observed that are deviations from the current existing theory. Thus, the financial crises of 2007-2009 should have been sufficient empirical evidence to indicate that the axiom- 
O problema principal, na visão do MPEPA, é que a perspectiva dominante na academia somente aceita como válidos aqueles trabalhos alinhados com seus métodos. Isso reforça o comportamento dito autista, já que a comunidade de economistas acadêmicos não raro passa a olhar para qualquer paradigma diferente desse como sendo menos cientifico, portanto, descartável. Essa exatidão abstrata, baseada num conjunto de axiomas que pretendem impor previsibilidade a um mundo imprevisível, tornou a ciência econômica viciada em abstração e formalização, vistas praticamente como condições sine qua non do método científico do paradigma mainstream..$^{23}$

Essa postura reflete, em última instância, certo dogmatismo. A postura de construir mundos econômicos abstratos tais que ocorram neles situações de equilíbrio único e estável tornou-se o dogma central da teorização mainstream, embora raramente isso seja reconhecido. ${ }^{24} \mathrm{O}$ equilíbrio assim obtido é tomado como modelo ideal, pano de fundo contra o qual comparar as realizações do mundo real. Mas a incapacidade da teoria de descrever o mundo real não é questionada - eis aí a natureza do dogma. É contra esse dogmatismo que o descontentamento do MPEPA se direciona ao criticar a criação de mundos imaginários em economia. Essa crítica também foi expressa pelos professores franceses, ao criticarem em sua carta a exclusão das teorias não-mainstream do ambiente de ensino e pesquisa em economia; desse modo, teorias com outras matrizes teóricas, que buscam explicar fenômenos econômicos sem recorrer à abstração matemática rigorosa são vistas como pouco científicas.

Essas críticas são compartilhadas por uma outra, de natureza interna (porque realizada por um praticante do mainstream), bastante vigorosa,

atic basis of the mainstream theory needs to be replaced."

23 Observe-se que essa perspectiva não é plenamente aceita por todos os críticos do mainstream. Colander, Holt e Rosser (2007), por exemplo, defendem a ideia de que mudanças estruturais na ciência econômica surgem, sim, a partir do próprio mainstream, cujo comportamento de grupo, em termos metodológicos, seria coeso, mas não necessariamente fechado a novas ideias. A perspectiva otimista desses autores, ao que parece, foi modificada após a crise de 2007-2008. Em 2008 um grupo de economistas, tendo Colander à frente, faria uma forte crítica ao fracasso da economia acadêmica em desprender-se de modelos teóricos com pouca aderência a problemas do mundo real (Colander et al., 2009).

24 Uma rara exceção a isso é encontrada Hahn (1984). Weintraub (2002) mostra que o resultado de Arrow e Debreu, normalmente apresentado como prova definitiva do equilíbrio geral, não foi facilmente aceito dentro da comunidade de economistas matemáticos nos anos 1960. Por isso esse autor levanta a questão de "quando uma prova é uma prova?" (Idem, 2002, p. 204). Já nos anos 1970 esse programa teria sido atingido em seus alicerces (Rizvi, 2007). Mais radical, Blaug (2007) questiona se a teoria do equilíbrio geral não seria a prova de que, em economia, o rei está nu. 
feita por Romer (2016). Este autor critica fortemente o estado da macroeconomia nas últimas três décadas. ${ }^{25}$ Romer questiona o comportamento de grupo fechado característico das correntes dominantes na macroeconomia, utilizando como provocação outra crítica: a crítica de Smolin (2007, cap. 16) aos teóricos de supercordas, na Física. Romer observa similaridade entre praticantes da macroeconomia desenvolvida a partir dos anos 1970 e as características que Smolin atribui aos teóricos de supercordas. Seriam sete características: i) tremenda autoconfiança; ii) comunidade científica monolítica; iii) um sentido de identificação com o grupo semelhante à identificação com grupos religiosos ou plataformas políticas; iv) forte delimitação da fronteira entre o grupo e outros especialistas; $v$ ) desrespeito/ desinteresse pelas ideias de especialistas de fora do grupo; vi) interpretação otimista de evidências, acreditando em declarações incompletas de resultados, ignorando a possibilidade da teoria estar errada; vii) falta de apreciação dos riscos do programa de investigação. Segundo Romer, uma prática científica com essas características tende a cair perigosamente para o viés do discurso de autoridade. Na crítica de Romer, o argumento principal é que o discurso de autoridade ganhou proeminência sobre a análise dos fatos, no fazer economia dentro dessas escolas. Assim,

The conditions for failure are present when a few talented researchers come to be
respected for genuine contributions on the cutting edge of mathematical modeling.
Admiration evolves into deference to these leaders. Deference leads to effort along
the specific lines that the leaders recommend. Because guidance from authority
can align the efforts of many researchers, conformity to the facts is no longer
needed as a coordinating device. As a result, if facts disconfirm the officially sanc-
tioned theoretical vision, they are subordinated. Eventually, evidence stops being
relevant. Progress in the field is judged by the purity of its mathematical theories,
as determined by the authorities. (Romer, 2016, p. 15-16).

A defesa dos resultados teóricos dessas correntes é feita por meio de metodologias marcadas por opacidade e questionável rigor teórico, principalmente, segundo Romer, por lançar mão de forma excessiva de variáveis imaginárias (não explicitamente admitidas assim) nos modelos. A crítica de Romer se aproxima, assim, daquela do MPEPA: "If the author can make up an imaginary variable, 'because I say so' seems like a pretty convincing answer to any question about its properties." (Romer, 2016, p. 13). ${ }^{26}$

25 A crítica é direcionada principalmente aos praticantes das escolas de Real Business Cycles (RBC) e Dynamic Sthocastic General Equilibrium (DSGE).

26 Vale apontar, não obstante, uma incoerência na própria crítica e postura de Romer: enquanto ele critica a opacidade dessas correntes da macroeconomia, não parece perceber que 


\subsection{0 cântico hipnótico das sereias: matematização e subserviên- cia em economia}

A crítica ao uso descontrolado da matemática, segundo ponto abordado pelo MPEPA, está igualmente relacionada ao terceiro tópico elencado no manifesto dos professores. A crítica não rejeita, nem poderia rejeitar, o uso da matemática como um instrumento para a teorização econômica, mas questiona seu uso como um fim em si mesma. Desde a revolução marginalista passou-se a utilizar o instrumental matemático na modelagem econômica. No entanto, a aparente beleza dessa formalização, vista como uma linguagem universalizada e sem ambiguidades que teria vantagens óbvias para a transmissão de conhecimentos científicos, transformou-se num drama para o fazer científico da economia. A matemática seduziu os economistas assim como as sereias seduziam os marinheiros na Odisséia. ${ }^{27}$

É preciso enfatizar o ponto mais grave desse desvio: o uso da matemática em economia muitas vezes tornou-se um fim em si mesmo, e isso limita os desenvolvimentos da ciência por duas razões, pelo menos. Em primeiro lugar, por ser a formalização um fim em si, quaisquer explicações teóricas não matematizadas passam a ser preteridas, particularmente nos journals mais difundidos, por modelos que sejam "fundamentados" em instrumental matemático, mesmo que em detrimento da realidade; o uso de matemática avançada tornou-se uma espécie de "selo de qualidade" para a economia. Segundo, porque para que se possa reduzir um sistema social complexo (de comportamento não necessariamente linear, passível de apresentar tendências explosivas, sem gravitação em torno de equilíbrios únicos) a um sistema estável de equilíbrio único (sem o qual as condições de otimalidade não se verificam), não se utiliza a matemática como um caminho que leve a modelagem até onde se puder chegar com ela, mas como uma trilha pré-definida que leve a modelagem exatamente ao ponto

a mesma crítica poderia ser feita à teoria ortodoxa básica por trás delas, isto é, à própria "microfundamentação" com base no modelo de equilíbrio geral de Arrow-Debreu.

27 Como comenta ironicamente Piketty, "the discipline of economics has yet to get over its childhood passion for mathematics (...) at the expense of historical research and collaboration with other social sciences. Economists are too often preoccupied with petty mathematical problems of interest only for themselves. This obsession with mathematics is an easy way of acquiring the appearance of scientificity without having to answer the far more complex questions posed by the world we live in." (Piketty, 2014, p. 32). Na mesma linha, Krugman escrevera: "As I see it, the economics profession went astray because economists, as a group, mistook beauty, clad in impressive-looking mathematics, for truth." (Krugman, 2009, p. MM36, The New York Times). 
de chegada que se desejava alcançar desde o princípio. ${ }^{28}$ Esses aspectos são apontados pelos docentes que manifestaram seu apoio ao MPEPA..$^{29}$

O que os professores denunciam é exatamente a ilusão, ademais bastante questionada no campo da epistemologia e da teoria do conhecimento, de que o grau de cientificidade de uma ciência é condicionado pelo nível de sua formalização matemática. Na economia, em especial, a vaidade de pretender-se parecida com uma hard science criou o duvidoso critério de validação de considerar pouco (ou nada) científicos trabalhos que não sejam formalizados. ${ }^{30}$ Mais grave ainda, essa postura exclusivista redunda na patologia de se desprezar campos inteiros do saber econômico, como a história econômica, a economia política, a crítica metodológica, e todas as escolas não ortodoxas, como sendo não científicas. ${ }^{31}$ Assim, a matematização aprofundou o comportamento autista da economia ortodoxa.

Torna-se fundamental discutir essa excessiva matematização na ciência econômica. A matematização é assim definida por Luperi e Fernandez (2014, p. 2):

Por matematização nós entendemos (...) o uso de qualquer instrumental matemático: equações, teoremas, o uso do cálculo diferencial, da topologia, etc. A simples presença de números, todavia, não caracteriza o processo de matematização: uma tabela com dados quantitativos, o cálculo de percentagens, o uso das quatro operações básicas, etc., certamente não caracteriza a matematização da economia.

28 Há outro risco inerente a essa atitude: não se utiliza a matemática de forma livre, mas de forma restrita. Não qualquer matemática, mas somente aquela matemática capaz de levar a teorização até onde se deseja, partindo-se das hipóteses necessárias para alcançar os resultados almejados. McCloskey (1994) chama isso de busca pelo hiperespaço das hipóteses. Um exemplo disso: teorias matemáticas extremamente complexas, mas que podem levar a equilíbrios múltiplos e sistemas não determinísticos, como a teoria do caos, são preteridas em boa parte das abordagens mainstream (Faggini e Parziale, 2012).

29 "[...] we denounce the naive and abusive conflation that is often made between scientificity and the use of mathematics. The debate on the scientific status of economics cannot be limited to the question of using mathematics or not." Disponivel em: <http://www.paecon.net/PAEtexts/Fr-t-petition. htm>. Acessado: 24 ago. 2015.

30 Nas palavras de Chick, "...economics is a subject so complex and interwoven that the achievement of cogent knowledge by any single method is impossible; therefore there is a scope and need for a variety of approaches. Formal methods cannot claim to be the only valid approach (...). The debate on that issue has hardly been joined, because of the hegemony of the formalists. Their certainty that any other approach is inferior or down right wrong, and the view that those who do not embrace formal techniques are against their use, has stifled debate" (1998, p.1859).

31 Existem exemplos de que o mainstream pode preservar os nomes das subdisciplinas internas da teoria econômica, não obstante modificando completamente seu foco e método, deixando-o no formato padrão de um saber matematizado de limitada aderência empírica. Temos entre tais exemplos a economia política e a economia industrial em suas versões ortodoxas, voltadas para a aplicação de teorias dos jogos. 
A definição proposta por Luperi e Fernandez enfatiza, portanto, que a simples presença de números em uma análise não caracteriza uma ciência matematizada. De acordo com esses autores, se esse critério de delimitação não fosse considerado "praticamente todas as ciências estariam matematizadas" (Idem, p. 2)

É a partir da ideia de que a formalização representa um grau mais elevado de cientificidade, que os economistas do mainstream entendem que a matematização apresenta-se como uma tendência natural para a criação de uma ciência mais rigorosa. Essa é a postura dominante desde os escritos de Jevons, mas ganhou força em autores como Samuelson, no sucesso da reformulação do modelo de equilíbrio walrasiano feita por Arrow e Debreu, e no encanto que tais resultados exerceram mais tarde em Friedman, Lucas e outros ardorosos defensores da ideia da economia como hard science. ${ }^{32}$

De fato, desde o fim do século XIX é possível identificar autores participando na transformação da economia em uma ciência matematizada, na tentativa de que pudesse ser reconhecida como uma ciência dura, espelhada na Física (Mirowski, 1989). Isso ignora as advertências de que os motivos do espetacular sucesso da matemática nas ciências duras não se verificam na economia (Gillies, 2004). Conforme a proposição de Luperi (2012, p. 56) "por trás do processo de matematização reside a ideia de que só o pensamento traduzível na forma matemática é respeitável em economia." Assim, é importante separar o que é meritório do que é patológico no uso da matemática em economia.

\subsubsection{Matemática como ferramenta para a Ciência Econômica}

A tendência descrita acima, iniciada no século XIX, ganhou força ao longo do século XX, especialmente em sua primeira metade, quando houve a crítica ao caráter pouco axiomático da matemática utilizada em economia (Von Neumann e Morgenstern, 1953). A partir dessa crítica, o uso da matemática ganhou novo impulso, levando a estabelecer os alicerces do mo-

32 Samuelson foi um dos responsáveis pela adoção do conceito da ergodicidade do sistema econômico como uma condição necessária para fazer ciência econômica (Samuelson, 1969). Lucas, em especial, escreveu que "Progress in economic thinking means getting better and better abstract, analogue models, not better verbal observations about the real world." (Lucas, 1981, p. 276). Não deixa de ser irônico que ele faça menção ao "mundo real" nessa proposição metodológica apologética da abstração matemática. 
delo de equilíbrio geral em bases axiomáticas a partir de meados dos anos 1950. Os principais expoentes dessa nova fase foram Samuelson, Arrow e Debreu, todos basicamente inspirados na crítica de Von Neumann e Morgenstern. De acordo com Ingrao e Israel (1990, p. 185-186), Von Neumann é "o cientista ideal para personificar o novo paradigma matemático" em economia. Estes economistas assumiram a responsabilidade de matematizar os assuntos de maior relevância, segundo sua ótica, entre aqueles que vinham sendo desenvolvidos nos mais de 150 anos anteriores. ${ }^{33}$

Samuelson (1947) argumentou em favor da matematização da ciência econômica, ao defender que é a formalização matemática a que torna possível dispor todas as partes da teoria de modo claro para sua transmissão de um economista para outro. Isto equivale a dizer que a matemática representaria o mais elevado grau de objetividade dentro da ciência econômica. Como observa Luperi (2012; 2015), essa visão reflete a perspectiva de que o processo de matematização da economia confere maior clareza, precisão e concisão na transmissão de conhecimentos teóricos em economia.

Esse segundo momento de mudança do discurso econômico na direção de maior rigor matemático acabou alcançando um impacto maior do que o da revolução marginalista, em termos qualitativos e quantitativos, pelo advento de um novo tratamento matemático para a reformulação mais rigorosa do modelo de equilíbrio geral (Luperi, 2012). Esses instrumentos matemáticos só ficaram disponíveis após a ocorrência da "revolução" na física matemática em começos do século XX. Uma nova noção de rigor das provas matemáticas estaria ligada à crise da Física datada do início do século XX (Weintraub, 2002). Antes dessa crise, a noção de rigor em economia era vinculada à aderência dos modelos à realidade. Todavia, esse rigor passou paulatinamente a ser identificado com a existência de consistência lógica em modelos formalizados. Essa nova maneira de compreender o rigor matemático orientou a demonstração do modelo de equilíbrio geral walrasiano, como reformulado por Arrow e Debreu nos anos 1950, transformando-se no paradigma central dentro dos programas de pesquisa mainstream. A partir dali o uso da matemática ocupou e assenhoreou-se da sala de estar da ciência econômica.

33 Segundo Mirowski (1991) existiram dois momentos de ruptura no discurso econômico. O primeiro ocorreu a partir de 1870 e se estendeu por duas ou três décadas, com a chamada Revolução Marginalista. Este processo estava enfrentando dificuldades quando foi revitalizado por uma segunda onda, ocorrida especialmente entre 1925 e 1936. 


\subsubsection{Problemas da matematização da economia}

A maior parte da crítica à excessiva matematização da economia não vem, obviamente, de dentro do mainstream, mas das correntes heterodoxas. No entanto, como parte das críticas que a economia vem sofrendo após a crise financeira de 2008, até dentro do mainstream tem surgido fortes questionamentos a respeito deste assunto. ${ }^{34}$ Mas são, de fato, as abordagens heterodoxas as que manifestam há muito uma postura mais questionadora em relação a isso. Essas escolas manifestam uma preocupação ampla com o uso desenfreado da matemática em economia, e com o alto grau de subserviência da última à primeira. Beed e Kane (1991, p. 583) identificaram sete críticas à excessiva matematização na teoria econômica:

i) A base axiomática não corresponde ao comportamento observável dos agentes do mundo real;

ii) O número de hipóteses empiricamente testáveis geradas pela economia matemática é pequeno, comparado ao volume de suas análises;

iii) Nem todos os fenômenos econômicos são naturalmente quantitativos, não se prestando diretamente à exposição matematizada;

iv) A tradução da descrição dos processos econômicos de uma linguagem natural (tal como o inglês ou qualquer idioma) para o formalismo da matemática pode ser ingênua e ilegítima;

v) Não há maneira objetiva de avaliar se uma formulação de economia mais matematizada é mais precisa que uma congênere menos matematizada;

vi) Não existe um melhor sistema de lógica matemática;

vii) Por causa de todos os problemas acima a matemática é, muitas vezes, um enfeite desnecessário para a teorização econômica sobre o mundo real (embora sirva para outros fins, em especial, a aceitação pelos pares).

Esses autores refletem uma percepção de que o maior problema da utilização excessiva da matemática na ciência econômica é o descolamento da realidade, decorrente de dois aspectos principais. De um lado, ela ocupa todo o espaço que poderia ser direcionado às análises diferenciadas (interdisciplinares, por exemplo) para a compreensão dos fenômenos. Por outro, pelo fato de que a realidade é sacrificada em nome do rigor formal, 34 Vide as já citadas críticas de Krugman (2009), Piketty (2014), Romer (2016). Ver também Faggini e Parziale, (2012). 
dirigido por uma abordagem que busca de forma teleológica argumentos matemáticos para se adequar à sua teoria, independente de qual seja ela. Isto significa dizer, em última instância, que se impõe que a realidade se adeque à teoria, e não o contrário.

O segundo tópico, por sua vez, compreende a maior parte das críticas levantadas por Beed e Kane (1991), também presentes nos manifestos do MPEPA e dos professores franceses em 2000. A crítica da matematização da economia, para uma parcela significativa dos economistas, mais especificamente, para o mainstream, é um debate ultrapassado. A validação da economia como ciência, para esse grupo, não pode prescindir desse formalismo, mesmo que em detrimento de maior aderência à realidade. $\mathrm{Na}$ posição do presente trabalho, porém, entende-se tratar-se de uma crítica séria e severa, bastante atual e pertinente, dado que tal falta de questionamento tem levado o fazer ciência econômica do mainstream a se isolar num mundo de abstrações de pouca relevância prática: acrescenta pouco ao conhecimento de como a economia funciona (em termos de ciência positiva) e resulta em recomendações irrealistas de política econômica (em seu caráter normativo).

Sem levar em conta esses fatores, aqueles que defendem a utilização da matemática de forma acrítica sustentam, de forma recorrente, que não existe representação do mundo real sem algum grau de abstração. Eles destacam que um mapa não pode ser tão preciso ao ponto de ser idêntico ao próprio território a ser mapeado. Esse argumento só poderia ser considerado válido, todavia, feitas as devidas ressalvas. $O$ mapa deve pelo menos apontar corretamente onde fica o Norte, bem como deve indicar os principais acidentes geográficos, a fim de que, mesmo sendo uma simplificação, possa orientar o viajante por esse território. A reflexão que se faz necessária consiste basicamente em traçar uma linha capaz de demarcar qual nível de abstração pode ser aceito e qual nível de distorção da realidade pode ser tolerado. Como ressalta Woo (1986. p. 14): "a questão real é se a distorção é 'controlável' ou não".

É importante que fique claro que não se propõe uma ciência econômica nada matematizada nem por parte dos estudantes que se envolveram no Manifesto inicial, nem pelos professores. A importância do uso de análises formais deve ser reconhecida. ${ }^{35} \mathrm{~A}$ crítica refere-se à aplicação da matemáti-

35 Pode-se ressaltar isso com base numa comparação de abordagens diferentes para o tratamento de um mesmo problema teórico geral, que foi de grande interesse em fins do sécu- 
ca como um fim de si mesma, não como uma ferramenta para a análise. De um modo geral, a economia é ensinada mediante o estudo de exercícios abstratos que apenas visam a aplicação de técnicas matemáticas; muitas vezes tais exercícios não apresentam aderência empírica, nem estão fundamentados em análises históricas, nem dialogam com outras ciências sociais. Essa combinação não atende à expectativa de conexão entre ensino, aprendizado e capacidade de atuar criticamente sobre a realidade factual. A teoria neoclássica raramente encara os fatos econômicos que se propõe analisar com uma abordagem compatível com a natureza complexa destes, preferindo uma matemática complexa à realidade complexa. $\bigcirc$ rigor do tratamento matemático e as dificuldades de lidar com a parte empírica tiram muito espaço da reflexão sobre a história dos fatos, sobre os comportamentos reais (não idealizados) dos agentes e sobre a maneira como as instituições funcionam.

O terceiro item central da exigência do MPEPA clamava por uma ciência econômica capaz de ter interface direta com a realidade. Não faltaram aqui exemplos para que os estudantes os elencassem; mas, além disso, devemos destacar que a crise de 2008 conferiu uma força especialmente dramática a estes argumentos, dado que essa crise não foi antecipada por economistas de renome dentro do mainstream. Como foi possível que, em um tempo tão "avançado" da teoria econômica, uma crise dessa magnitude não fosse "prevista" pelos estudiosos da área? Isso tornou-se uma questão curiosa no imediato pós-crise. ${ }^{36}$ A maior conexão da teoria com a realidade parece reclamar, portanto, uma forma pluralista de fazer economia. Esse é objeto da próxima seção.

lo XIX e início do século XX. Mitchell (1913), Schumpeter (1934), Keynes (1936) e Kalecki (1954) trataram, na primeira metade do século XX, dos ciclos econômicos. Mitchell fez uso abundante das estatísticas disponíveis. Schumpeter não usou uma equação sequer para descrever seu o processo de inovação. Keynes e Kalecki formalizaram alguns aspectos de sua abordagem sem, no entanto, deixarem a análise econômica e a aderência empírica à mercê do instrumental matemático que aplicaram.

36 Essa simples pergunta foi endereçada, por exemplo, pela Rainha Elisabeth II aos economistas britânicos após o estouro da crise. É preciso lembrar que tinham surgido antes dessa data análises de economistas ressaltando a existência de indícios de que algo grave estaria a caminho. Textos de imprensa de Nouriel Roubini e de Robert Schiller, por exemplo, chamavam a atenção para a aproximação de algum evento crítico no mercado financeiro. Como observa Haldane (2012), não haveria mesmo dados estatísticos suficientes para que um evento dessa magnitude pudesse ser previsto: seriam necessárias séries históricas financeiras da ordem de 250 anos de observações para que crises como as de 1929 ou de 2008 pudessem entrar no radar de uma função de distribuição de probabilidade. 


\section{As questões do pluralismo das abordagens em eco- nomia}

O terceiro ponto da crítica dos estudantes refere-se ao pedido de que thes seja apresentada uma ciência mais pluralista; essa reivindicação também está presente nas reivindicações dos docentes ("a necessidade de uma pluralidade de abordagens adaptada à complexidade dos objetos analisados") bem como no relatório confeccionado por Fitoussi (2001). ${ }^{37}$ Nesse espírito, Fullbrook, um dos líderes do movimento da World Economics Association, associação de economistas críticos do mainstream cujo impulso inicial pode ser localizado no MPEPA, defende a necessidade de apresentar diversas visões aos estudantes:

Neoclassical economics' monopoly in the classroom and its prohibition on critical
thinking means that it brainwashes successive generations of students into vie-
wing economic reality exclusively through its concepts, which more often than
not misrepresent or veil the world, especially today's world (...) if society were to
learn to think about economic matters outside the neoclassical conceptual system,
it would almost certainly choose different policies. (Fullbrook, 2008, p.7)

Sucintamente, pluralismo pode ser entendido como a avaliação de que a existência de diferentes visões de alguma coisa, ou seja, a existência de pluralidade, é algo positivo (Fernández, 2011). Em linhas gerais, pluralismo em economia diz respeito à aceitação de que os fatos econômicos, por sua complexidade e interligação com múltiplos outros fatores (e.g.: históricos, políticos, sociais, institucionais, ideológicos, etc.) devem ser estudados sob diferentes perspectivas analíticas, permitindo assim uma maior compreensão deles. Bianchi (1992, p. 139) ressalta a autonomia e multiplicidade dos grupos sociais, o que a leva a considerar o pluralismo como uma postura avessa a totalitarismos e dogmatismos.

Em termos históricos, as discussões referentes ao pluralismo remontam aos escritos clássicos da economia e da metodologia econômica. Os primeiros economistas expressaram uma tradição teórica e metodológica bastante abrangente. ${ }^{38}$ Em particular, encontram-se elementos plu-

37 É possível encontrar mais informações sobre o relatório em: <http://www.paecon.net/ PAEhistory02.htm>. Acesso em 07/02/2017.

38 Vale notar que o próprio Jevons no final de seu clássico "Teoria da Economia Política", criticou a monopolização da ciência econômica por apenas uma vertente teórica - no caso, Jevons reclamava da dominância da economia clássica de Mill, que impedia o progresso no sentido da aceitação das ideias marginalistas. Os autores agradecem aos comentários de um(a) parecerista que nos iluminou esse ponto. 
ralistas nas ideias de Mill (1843) - provenientes de seu Sistema de Lógica - e nos escritos de Neville Keynes (1891[1917]). Tais ideias refletem o que se pode denominar de proto-pluralismo (Borba, 2013, p. 32). O contexto da ideia inicial do aqui chamado proto-pluralismo é identificado na obra de N. Keynes e está relacionado à disputa por espaço que ocorria naquele momento entre a escola (neo)clássica inglesa e a escola histórica alemã (Bianchi, 1992).

É evidente que esta disputa -contemporânea daquela entre os historicistas alemães e a escola austríaca, denominada Methodenstreit ${ }^{39}$ - associa-se a um debate ainda mais antigo e ainda sem conclusão, a respeito da questão da oposição dedução versus indução como o método adequado para as ciências. N. Keynes (1917, p. 172) postulava ser um erro colocar esses métodos como alternativas excludentes. Percebe-se aqui uma inclinação ao que atualmente trata-se como pluralismo: a percepção de que dois (ou mais) métodos podem ser utilizados de forma concomitante, de modo a trazer benefícios à ciência. A perspectiva de N. Keynes expõe os limites do monismo metodológico para o desenvolvimento da ciência econômica. Como argumenta Bianchi (1992, p. 138): "Cada um deles tem seus méritos e suas limitações, e a habilidade do cientista é revelada precisamente na sabedoria com que combina os méritos e se precave contra as limitações." Na mesma direção, Fernandez (2011, p. 149) afirma que:

Nessa perspectiva, as escolas (ou programas de pesquisa) são vistas como diferentes espécies que concorrem entre si, mas cada uma das quais tem um nicho ecológico diferente. E assim não há uma espécie que seja melhor para todos os ecossistemas, as diversas escolas podem fornecer boas respostas e insights para problemas muito diferentes.

A proposta preliminar - proto-pluralismo - antecedeu uma refinação realizada por Caldwell (1982), sugerindo o que é conhecido como "pluralismo crítico", proposição que recupera as ideias do racionalismo crítico preconizado por Popper, com o objetivo de esquivar-se da eventual anarquia que poderia ser decorrente do pluralismo. O pluralismo crítico, de acordo com Caldwell (1990, p. 104) "It is not a full-fledged position, but neither is it so vague that it cannot be articulated". De modo resumido, a preocupação de Caldwell centra-se em estipular parâmetros para que o pluralismo não seja confundido com o anarquismo metodológico, ou seja, que não pudesse ser visto como uma perspectiva que dá espaço

39 Termo de origem alemão, traduzido como batalha dos métodos. 
para propostas que não respeitam nenhuma regra. Cavalieri (2009, p. 9) ressaltou que: "o pluralismo crítico não pretende ser uma filosofia da ciência. O pluralismo crítico é, antes de tudo, uma posição de economista." Cavalieri compilou os critérios estabelecidos por Caldwell com o objetivo de prover uma orientação acerca do que seria assim aceitável/ desejável no fazer ciência econômica:

(1) A busca de um critério universal de apreciação e escolha de teorias é desaconselhada; (2) Ênfase no trabalho crítico: a tarefa do metodólogo é mostrar os pontos fortes e os fracos de um determinado programa de pesquisa; (3) Ao fazer a reconstrução racional de um programa de pesquisa, o metodólogo deve preocupar-se em mostrá-lo na sua forma mais forte; (4) Na formulação de críticas a um determinado programa de pesquisa, devem ser levados em conta os problemas para os quais o programa procura respostas. Um programa pode ser considerado adequado para alguns problemas e não para outros. (Cavalieri, 2008, p. 5)

Em linhas gerais, Caldwell preocupou-se com a necessidade imperiosa de dar espaço ao "novo" dentro da Economia; isso exige críticas livres de dogmas, diminuindo assim, conforme Bianchi (1992, p. 140), a incomensurabilidade entre as teorias, promovendo ademais o diálogo entre diferentes programas de pesquisa. Em outras palavras, a ideia de dar espaço à novidade na Economia exige prestar atenção às teorias novas com metodologias alternativas e, possivelmente, antagônicas às normalmente aceitas. ${ }^{40}$

Caldwell acredita, em defesa do pluralismo crítico, que a coexistência de teorias e métodos diferentes é benéfica para o desenvolvimento da ciência. O desejo de que existam críticas não dogmáticas é condição sine qua non para a proliferação de novas teorias. Desse modo, o diálogo entre economistas de programas de pesquisa científica distintos seria incentivado, o que poderia trazer grandes contribuições ao desenvolvimento da ciência. Ainda que se tenha em consideração a questão da incomensurabilidade dos paradigmas (Kuhn, 2003), ${ }^{41}$ considera-se que, tomando como algo de-

40 Há ideias heterodoxas não necessariamente novas que o mainstream ignora até hoje, bem como outras que ignorou durante muitos anos, e quando as assimilou, o fez de maneira parcial. A "descoberta", feita nos anos 1980 pela ortodoxia, da importância dos conceitos de instituições ou de rendimentos crescentes à escala, por exemplo, ocorreu com significativo atraso em relação a diversas correntes heterodoxas que já vinham destacando a importância desses conceitos. Esse tipo de "atraso" é recorrente em economia (Cavalieri, 2009). O novo pode significar, simplesmente, aceitar a abordagem diferente.

41 Tossato (2012, p. 493) acrescenta que "incomensurabilidade pode significar, no limite, a impossibilidade radical de decisão sobre qual teoria é a mais adequada para um determinado ramo científico, pois a incomensurabilidade em suas diversas formas implica que não há possibilidade de escolha entre teorias. Assim, teorias distintas pertencem ou a mundos diferentes ou são expressas em termos intraduzíveis de uma teoria para outra teoria distinta, 
sejável a promoção da novidade e o diálogo entre programas diferentes, haveria maior densidade no debate entre teorias. ${ }^{42}$

Outros autores expuseram e trataram questões referentes ao pluralismo de forma propositiva, como Feyerabend (2011) e Lacey (1999), com enfoque no pluralismo metodológico. Também Dow (2004:1; 2004:2; 2015), com sua proposta de um pluralismo estruturado em economia e, ainda antes, Dilthey (1989), caminham na mesma direção, ao defenderem o que é conhecido como epistemologia da diferença para as ciências sociais e humanas. Samuels $(1993$; 1997) também se coloca como um forte defensor de um pluralismo que seja o mais aberto possível.

Alguns autores pluralistas enfatizam que o pluralismo não pode ser considerado um tipo de anarquismo metodológico, pois ele não reflete uma postura meramente relativista. ${ }^{43} \mathrm{O}$ que se propõe é uma atitude mais aberta e crítica, voltada para tornar a práxis do pensar a economia de modo pluralista, fazendo disso hábito e postura ética enriquecedora (Fernandez, 2011; Borba, 2013). Acredita-se que uma posição pluralista seja central para o enriquecimento da ciência econômica. Tal postura é ainda mais rica se considerar-se que seu escopo vai além de uma ciência social aplicada em particular, como a economia: há espaço para o pluralismo em mais áreas do conhecimento humano, como proposto por Fernandez (2011, p. 147):

Em realidade, a superioridade do pluralismo como atitude metodológica não é uma particularidade da economia. Em princípio, poderíamos pensar que a única atitude compativel com a defesa de uma sociedade democrática é permitir que diferentes vozes se manifestem, o que valeria para a ciência como conjunto e para cada uma de suas disciplinas em particular. Por isso, se não temos respostas $100 \%$ garantidas, o importante é deixar que todo mundo fale.

A posição desses autores é a mesma comungada pelo presente trabalho e, acredita-se, com os anseios manifestados por estudantes e professores alinhados ao MPEPA: a defesa de uma Ciência Econômica plural traria benefícios, em termos de capacidade de entendimento dos fenô-

ou ambas as coisas."

42 Como exemplificado por Bianchi (1992, p. 140): "entender os austríacos em seus próprios termos evita que os debates se tornem meramente semânticos e ajuda austríacos e não-austríacos a fundamentarem melhor suas teorias".

43 As críticas mais comuns feitas à ideia de pluralismo em economia postulam que: i) o pluralismo ocasiona anarquia metodológica; ii) o pluralismo não consegue distinguir boas teorias das ruins; iii) o pluralismo não consegue se estabelecer e por isso não passa de uma "posição interina." Alguns comentários sobre estas questões encontram-se em Fernández (2011). 
menos econômicos, que superam as críticas mencionadas. Mais ainda: dado o estágio atual de crítica ao mainstream, a ciência econômica precisa abrir-se para uma reflexão epistemológica profunda no modo de fazer ciência econômica.

É importante ressaltar que a prática do pluralismo está relacionada com um compromisso ético por parte dos economistas e com a reformulação do modo de pensar da comunidade científica em prol de um posicionamento mais aberto, menos hermético e não dogmático, com espaço para novas teorias e programas de pesquisa. É importante considerar que, dada a realidade complexa da economia, cada teoria pode ser capaz de lançar luz sobre alguma parcela da realidade, mas tratá-la em sua totalidade exige integrar diversas perspectivas. A maior compreensão resulta especificamente da composição que várias análises permitem, ao serem consideradas juntas, de formas complementares ou às vezes antagônicas, mas sempre propiciando um debate mais enriquecedor.

A imprescindibilidade do pluralismo implica que não deve haver apenas um método em economia, mas muitos, livres de dogmas; não apenas uma voz que se eleva por sobre as demais, calando os dissidentes, mas uma postura aberta a ouvir o que os demais têm a dizer; não uma escola ou grupo dominante encarnando a própria autoimagem da ciência, mas uma clara percepção de que os economistas não se pautam por um pensamento único, monolítico, autorreferenciado e imune a críticas. A expectativa é que um aparato teórico mais amplo possa elevar a qualidade do debate, aumentando a capacidade descritiva e preditiva da ciência. Em especial, isto contribuiria para que a interdisciplinaridade pudesse tornar-se realidade em economia. A crítica livre de dogmas e o debate franco entre escolas que se respeitam como alternativas, até mesmo concorrentes, mas não como "certas" versus "erradas", "canônicas" versus "heréticas", por utilizarem métodos ou fundamentos diferentes, melhorará a comunicação entre os economistas das mais diversas linhas de pensamento, acrescentando valor científico às críticas e densidade ao saber econômico. ${ }^{44}$

44 Vale observar que essa foi uma das características da ciência econômica entre fins do século XIX e início do século XX, quando vista com o devido distanciamento temporal. Havia novas explicações para os fenômenos observados, e havia escolas concorrentes sem haver ainda, de forma bem definida, uma escola "dominante". Uma análise desse processo foi realizada por Shackle (1967). 


\section{Considerações finais}

Em face da crise vivida pela ciência econômica em tempos recentes, e levando em conta as reflexões críticas feitas nos últimos anos por economistas e metodólogos a respeito das limitações da ciência econômica, o presente trabalho buscou avaliar as questões levantadas pelos proponentes do MPEPA, no intuito de contribuir para as discussões na área de metodologia e para a reformulação do ensino de economia. Além disso, buscou-se realizar uma crítica metodológica ao dogmatismo que se instaurou na ciência.

A ideia daqueles estudantes, comungada pelo presente trabalho, é a da necessidade da abertura da ciência econômica a abordagens não dogmáticas, restringindo a formalização matemática irrealista, e questionando a pretensão de que deva existir uma corrente única de pensamento; seria assim possível um caráter interdisciplinar, imprescindível dada a complexidade das sociedades modernas. Essas são as linhas mestras nas propostas dos estudantes franceses.

O ponto fundamental das reivindicações do MPEPA é por conferir maior espaço a abordagens não mainstream no ensino e na pesquisa em economia. Essa é uma reivindicação por maior pluralismo e por maior abertura à interdisciplinaridade. A ideia é que não há necessidade de que uma teoria/ método seja entendida como a única "correta", em detrimento de outras, de forma que haja espaço para visões alternativas, cada qual lançando o seu feixe de luz possível na realidade. A partir de uma postura pluralista, o dogmatismo cede espaço ao diálogo e às críticas, capazes de impulsionar o desenvolvimento da ciência econômica. Com base nessa análise, acredita-se ter evidenciado a relevância e atualidade do Movimento dos estudantes e professores franceses, bem como de outros movimentos similares que têm lutado em anos recentes para que a economia reencontre seu caminho como ciência social aplicada. Só assim será possível torná-la capaz de compreender e explicar o mundo econômico real, dando um salto qualitativo para além das abstrações e do dogmatismo teórico, herméticos à realidade e particularmente inábeis em prever e remediar os efeitos de cataclismos que podem ocorrer em sistemas econômicos, como as grandes crises, ou insensíveis às muitas outras questões reais que a complexidade do mundo apresenta ao pensador de economia. 


\section{Referências}

ANDRADE, R. P. A construção do conceito de incerteza: uma comparação das contribuições de Knight, Keynes, Shackle e Davidson. Nova Economia, 21 (2), p. 171-95, 2011.

BEED, C. KANE, O. What Is the Critique of the Mathematization of Economics? Kyklos, 44 (4), p. 581-612, 1991.

BIANCHI, A. M. Muitos métodos é o método: a respeito do pluralismo. Revista de Economia Política, 12, (2), p.135-142, 1992.

BLAUG, M. The Formalist Revolution of the 1950s. In Samuels, W., Biddle, J. \& Davis, J.B. (eds.), A Companion to the History of Economic Thought. Malden (MA): Blackwell, 2007, p. 395-410.

BORBA, E. O Pluralismo Enquanto Alternativa ao Monismo Metodológico na Economia. Disponível em: <http://cnm.ufsc.br/files/2014/01/Monografia-do-eduardo-de-Borba.pdf>. Acesso em: 19 out. 2015.

CALDWELL, B. Beyond Positivism: Economic Methodology in the Twentieth Century. London: George Allen \& Unwin, 1982.

CALDWELL, B. The Methodology of Scientific Research Programmes in Economics: Criticism and Conjectures. In: CALDWELL, B. The Philosophy and Methodology of Economics. Cheltenham: Edward Elgar, 1990.

CALDWELL, B. Commments: varieties of pluralism. In: SALANTI, A. SCREPANTI, E. Pluralism in Economics: new perspectives in history and methodology. Cheltenham: EAEPE \& Edward Elgar, 1997.

CAVALIERI, M. A. R. Quanto evoluíram os evolucionários? Um ensaio pluralista sobre a maturidade de um programa de pesquisa em economia. Economia Ensaios, 23 (1), p. 1-23, 2008.

CAVALIERI, M. A. R. Sobre os porquês do pluralismo em economia: aproximações de uma alternativa historicista. Pesquisa \& Debate, 20 (1), p. 165-187, 2009.

CHICK, V. On knowing one's place: the role of formalism in Economics. Economic Journal, 108 (November): p. 1859-1869, 1998.

COLANDER, D. The death of Neoclassical economics. Journal of the History of Economic Thought, 22, p. 127-143, 2000.

COLANDER, D. HOLT, R. ROSSER, B. The Changing Face of Mainstream Economics. Review of Political Economy, 16 (4): 485-499, 2007.

COLANDER, D. ; FÖLLMER, H.; HAAS, A. ; GOLDBERG, M.; JUSELIUS, K.; KIRMAN, A.; LUX, T.; SLOTH, B. The Financial Crisis and the Systemic Failure of Academic Economics. Copenhagen: Department of Economics/University of Copenhagen: Discussion Papers n. 09-03, 2009. Disponível em: <http://papers.ssrn.com/sol3/papers.cfm?abstract_ $\mathrm{id}=1355882>$.

COMISSION ON GRADUATE EDUCATION IN ECONOMICS. Report of the Comission on Graduate Education in Economics. Journal of Economic Literature, 29(September): 103553. 1991. 
DANZINGER, S.; VAN DER HAAG, J.; SMOLENSKY, E.; TAUSSIG, M. K.The life cycle hypothesis and the consumption behavior of the elderly. Journal of Post Keynesian Economics, 5, p. 224-6, 1982-1983.

DAVIDSON, P. Is economics a Science? Should economics be rigorous? Disponível em: <http: //econ.utk.edu/documents/davidsonpapers/realworld\%20econrview(2).pdf $>$. Acesso em: 15 ago. 2015.

DAVIDSON, P. Post Keynesian macroeconomic theory: a foundation for successful economic policies for the twenty-first century. Cambridge: Edward Elgar, 1994.

DEQUECH, D. Neoclassical, Mainstream, Orthodox and Heterodox Economics. Journal of Post Keynesian Economics, 30, 2007, p. 279-302.

DILTHEY, W. Introduction to the Human Sciences. Edited by R. A. Makkreel \& F. Rodi; trad. Michael Neville. New Jersey: Princeton University Press, 1989. (Selected Works, v. I).

DOW, S. Reorienting Economics: Some Epistemological Issues. Journal of Economic Methodology, 11 (3), 2004:1, 307-12.

DOW, S. Structured Pluralism. Journal of Economic Methodology, 11 (3), 2004:2, 275-90.

DOW, S. Heterodox Economics: A Commom Challenge to Mainstream Economics? In: Macroeconomics and Macroeconomic Policies: Alternatives to the Orthodoxy' Conference, Berlin, 28-9 Setembro, 2005. Disponível em: <http://www.boeckler.de/pdf/v_2005_10_28_ dow.pdf $>$. Acesso em: 13 out. 2015.

DUPUY, J. P. Economy and the future: a crisis of faith. East Lancing: Michigan State University Press, 2014.

FAGGINI, M. PARZIALE, A. The failure of economic theory: lessons from chaos theory. Modern Economy, 2012, 3, p. 1-10.

FERNANDEZ, R.G. A metodologia como argumento a favor de uma economia pluralista. In: Guilhoto, J.; Duarte, P. G.; Silber, S. (Org.). O Brasil e a ciência econômica em debate Volume 2 - O estado da arte em economia. São Paulo: Saraiva, 2011, p. 137-152.

FERRARI FILHO, F.; ARAÚJO, J. P, Caos, Incerteza e teoria pós-keynesiana, 2000. Disponível em: <http://www.ufrgs.br/ppge/pcientifica/2000_02.pdf>. Acesso em: 12 ago. 2015.

FEYERABEND, P. Contra o método. 2 ed. São Paulo: Editora Unesp, 2011.

FITOUSSI,J.P. L'enseignement supérieur des sciences économiques en question. Rapport au ministre de l'Education nationale. Paris: Fayard, 2001.

FRIEDMAN, M. The methodology of positive economics. In: Essays on positive economics. Chicago University Press, 1966; p. 3-16, 30-43.

FULLBROK, E. The crisis in economics. Kentucky: Routledge, 2003.

FULLBROK, E. Introduction. In FULLBROK, E. (org), Pluralist Economics. London \& New York: Zed Books, 2008.

GILLIES, D. Can mathematics be used successfully in Economics? In Fullbrook, E. (org.). A Guide to What's Wrong with Economics. London: Routledge, 2004, p. 187-197.

HAHN, F. Equilibrium and Macroeconomics. Oxford: Basic Blackwell, 1984.

HALDANE, A. The Dog and the Frisbee. Federal Reserve Bank of Kansas City's $36^{\text {th }}$ Eco- 
nomic Policy Symposium - "The Changing Policy Landscape", Jackson Hole, Wyoming, August, 2012. Bank of England Speeches and Archives, 2012. Disponível em: <http:// www.bankofengland.co.uk/publications/Documents/speeches/2012/speech596.pdf>. Acesso em: 2 mar. 2016.

HAMILTON, James D. (1994). Time Series Analysis. Princeton (NJ): Princeton University Press.

INGRAO, B.; ISRAEL, G. The Invisible Hand: Economic Equilibrium in History of Science. Cambridge, Massachusetts: MIT Press, 1990.

KALECKI, M. Theory of Economic Dynamics. J. Osiatynsky (ed.). Collected Works of Michal Kalecki, Vol. II, 1991 (Oxford: Oxford University Press), 1954 [1991].

KEYNES, J. M. A Treatise on Probability. New York: Cosimo Classics, 1921 [2006].

KEYNES, J. M. The general theory of employment, interest and money. The Collected Writings of John Maynard Keynes, Vol VII. Donald Moggridge (Ed.). Cambridge: Macmillan/Cambridge University Press, 1936 [1973].

KEYNES, J. N. The escope and Method of Political Economy, Nova York: University Press, 1917.

KNIGHT, F. H., Risk, Uncertainty and Profit. Boston (MA): Hart, Schaffner \& Marx, 1921.

KRUGMAN, P. How did economists get it so wrong? The New York Times Magazine September, 6, 2009.

KUHN, T. S. A Estrutura das Revoluções Científicas. São Paulo: Perspectiva, 2003

LACEY, H. Is science value free? Values and scientific understanding. Londres: Routledge, 1999.

LAWSON, T. Reorienting Economics. Kentucky: Routledge, 2003.

LEE, F. A History of Heterodox Economics: challenging the mainstream in the twentieth century. London \& New York: Routledge, 2009.

LUCAS, R. E. Studies in business cycle theory. Cambridge (MA): The MIT Press. 1981.

LUCAS, R. E.; SARGENT, T. J, Rational Expectations of Econometric Practices. University of Minesotta Press, 1981, p. xi-xii.

LUPERI, M. M. S. The general equilibrium theory as economic metatheory. Brazilian Journal of Political Economy, 30, 2015, p. 306-24.

LUPERI, M. M. S. Três Ensaios Críticos Sobre o Processo de Matematização da Economia no Brasil e no Mundo. Tese de Doutorado em Economia, FGV/EESP, 2012.

LUPERI, M. M. S.; FERNANDEZ, R. G. Os impactos da crise na física e na matemática do início do século XX sobre o discurso econômico contemporâneo. Trabalho apresentado no XIX Encontro Nacional de Economia Política, Florianópolis, 2014.

MÄKI, U. (1997). The One World and the Many Theories. In Salanti, A.; Screpanti, E. Pluralism in Economics: New Perspectives in History and Methodology. Cheltenham \& Brookfield: Edward Elgar, 1997, p. 37-47.

MANDELBROT, B. Towards a second stage of determinism in Science. Interdisciplinary Science Review, 12, 1987, p. 117-127.

McCLOSKEY, D. N. Knowledge and persuasion in economics. Cambridge: Cambridge University Press, 1994.

McCLOSKEY, D. N. Three Books of Oomph. Eastern Economic Journal, v. 27, n. 1, p. 115-118, 
2001.

MIROWSKI, P. From Mandelbrot to chaos in economic theory. Southern Economic Journal, 57; 1986, p. 289-307.

MIROWSKI, P. More Heat than Light: Economics as social physics, physics as nature's economics. New York: Cambridge University Press 1989.

MIROWSKI, P. The When, the How and the Why of Mathematical Expression in the History of Economic Analysis. Journal of Economic Perspectives, 5(1), 1991, p. 145-157.

MITCHELL, W.C. Business Cycles. Berkeley: University of California Press, 1913.

MOHN, K. Autism in Economics? A Second Opinion. Forum for Social Economics, 39 (2), 2010, p. 191-208.

NELSON, R. R. As fontes do crescimento econômico. Campinas: Editora da Unicamp, 2005.

PIKETTY, T. Capital in the twenty-first century. Cambridge (MA): Belknap Press/Harvard University Press, 2014.

POSNER, R. A. How I Became a Keynesian: Second thoughts in the middle of a crisis. The New Republic, September, 23, 2009:1.

POSNER, R. A. A failure of capitalism: the crisis of '08 and the descent into depression. Cambridge: Harvard University Press, 2009:2.

POSNER, R. A. The Crisis of Capitalist Democracy. Cambridge: Harvard University Press, 2010.

RIZVI, S.T.A. Postwar neoclassical microeconomics. In: Samuels, W., Biddle, J. \& Davis, J.B. (eds.), A Companion to the History of Economic Thought. Malden (MA): Blackwell, 2007, p. 377-394.

ROMER, P. The trouble with macroeconomics. The Commons Memorial Lecture of the Omicron Delta Epsilon Society/Stern School of Business - New York University, January, 5, 2016.

SALANTI, A. Introduction. In:Salanti, A.; Screpanti, E. Pluralism in Economics: New Perspectives in History and Methodology. Cheltenham \& Brookfield: Edward Elgar, 1997, p. 1-10.

SALANTI,A.; SCREPANTI, E., eds. Pluralism in Economics: new perspectives in history and methodology.Cheltenham \& Brookfield: Edward Elgar, 1997.

SAMUELS, W. In (Limited but Affirmative) Defence of Nihilism. Review of Political Economy 5 , 2 (1993): 236-244.

SAMUELS, W. The Case for Methodological Pluralism. In Salanti, A.; Screpanti, E., Pluralism in Economics: New Perspectives in History and Methodology. Cheltenham\& Brookfield: Edward Elgar, 1997, p. 67-79.

SAMUELSON, P. What classical and neoclassical theory really was. In CLOWER, R. W (ed.). Monetary theory. London: Penguin, 1969, p. 184-5.

SAMUELSON, P. Foundations of economic analysis. Boston: Harvard University Press, 1947 (Enlarged ed., 1983).

SCHUMPETER, J. A. The Theory of Economic Developmnet: an inquiry into profits, capital, credit, interest, and the business cicle. (16th printing). Brunswick (New Jersey): Transaction Publishers, 1934 [2012].

SHACKLE, G. L. S. The years of high theory: invention \& tradition in economic thought $1926-$ 
-1939. Cambridge: Cambridge Univesity Press, 1967.

SMOLIN, L. The trouble with Physics: the rise of String Theory, the fall of a science, and what comes next. Boston: Houghton Mifflin Harcourt, 2007.

STIGLITZ, J. Reconstructing macroeconomic theory to manage economic policy. NBER Working Paper No. 20517, September, 2014.

TOSSATO, C. R. Incomensurabilidade, comparabilidade e objetividade. Sci. stud., São Paulo, v. 10, n. 3, p. 489-504, 2012 . Disponível em: <http://www.scielo.br/scielo.php?script=sci_ arttext\&pid=S1678-31662012000300004\&lng=en\&nrm=iso $>$.http://dx.doi.org/10.1590/ S1678-31662012000300004>.

VON NEUMANN, J.; MORGENSTERN, O. Theory of games and economic behavior. $3^{\text {rd }}$ ed. Princeton (NJ): Princeton University Press, 1953.

WEINTRAUB, E. R. How Economics Became a Mathematical Science. Durham and London; Duke University Press, 2002.

WOO, H. K. H. What's Wrong with Formalization in Economics - An Epistemological Critique. Victoria Press, 1986.

\section{Sobre os autores}

Daniel de Santana Vasconcelos - daniel.s.vasconcelos@ufsc.br

Universidade Federal de Santa Catarina - UFSC, Florianópolis, Santa Catarina, Brasil. ORCID: http://orcid.org/0000-0001-9569-2991.

Maisa Goulart S. Ribeiro - maisagsr@gmail.com

Universidade Federal do ABC - UFABC, São Bernardo do Campo, São Paulo, Brasil. ORCID: http://orcid.org/0000-0003-0972-2248.

Ramon García Fernandez - ramon.garcia.fernandez@gmail.com Universidade Federal do ABC - UFABC, São Bernardo do Campo, São Paulo, Brasil. ORCID: https://orcid.org/0000-0002-4198-0792.

\section{Sobre 0 artigo}

Recebido em 11 de agosto de 2016. Aprovado em 02 de fevereiro de 2017. 